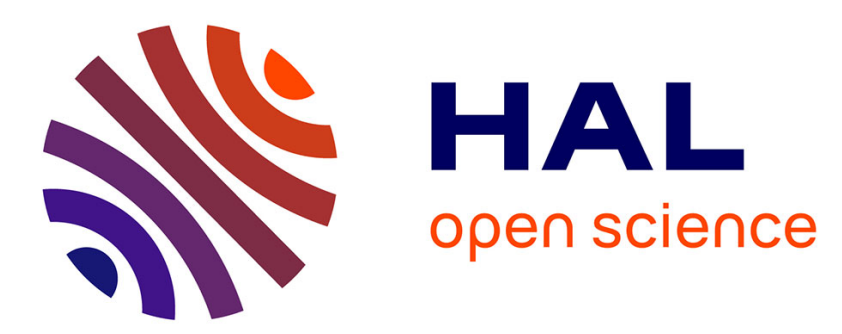

\title{
The making of health:: a reflection on the first 10 years in the life of a journal
}

\author{
Alan Radley, Julianne Cheek, Christian Ritter
}

\section{To cite this version:}

Alan Radley, Julianne Cheek, Christian Ritter. The making of health:: a reflection on the first 10 years in the life of a journal. Health:, 2006, 10 (4), pp.389-400. 10.1177/1363459306067309 . hal-00571425

\section{HAL Id: hal-00571425 \\ https://hal.science/hal-00571425}

Submitted on 1 Mar 2011

HAL is a multi-disciplinary open access archive for the deposit and dissemination of scientific research documents, whether they are published or not. The documents may come from teaching and research institutions in France or abroad, or from public or private research centers.
L'archive ouverte pluridisciplinaire HAL, est destinée au dépôt et à la diffusion de documents scientifiques de niveau recherche, publiés ou non, émanant des établissements d'enseignement et de recherche français ou étrangers, des laboratoires publics ou privés. 


\author{
Alan Radley, Julianne Cheek \& Christian \\ Ritter \\ Loughborough University, UK, University of South Australia, \\ Australia \& Kent State University, USA
}

\begin{abstract}
This introduction to the Tenth Anniversary Issue surveys articles that have been published in health: since its launch. Reviewing the original aims of the journal, the editors discuss some of the main issues that authors have raised, both about health and illness. Focusing upon articles that have been published in this particular journal, we discuss the way that new medical technologies - particularly global ones - have shaped ideas about disease and its treatment, and in consequence about what 'good health' should be. Related to the growth in medical and other technology - not least the rise of the Internet during the life of this journal - is the number of articles that discuss the rights of patients and the establishment of what might be termed an 'illness culture'. We conclude that there continues to be more to health than it being the background to illness or disease, and ask the question: should the 'taken for grantedness' of health be taken for granted any longer?
\end{abstract}

KEYWORDS globalization; health; illness; local culture; medical technology; uncertainty

ADDress Alan Radley, Department of Social Sciences, Loughborough University, Loughborough, Leics. LE11 3TU, UK. [Tel: +44 (0)1509 223356; fax: +44 (0)1509 223944; e-mail: A.R.Radley@lboro.ac.uk]

\title{
Introduction
}

The first issue of health: appeared in July 1997. In the opening editorial the editors set out the background against which this new journal was founded (Radley et al., 1997). This included a concern with individual rights in the context of increasing inequalities in some post-industrialized countries; the development of new medical technologies and competing claims to access and information; the growing coverage of health issues in the media (though not the Internet!); the spread of HIV/AIDS; the interest in alternative medicine and the demand for medical expertise in the pursuit of improved 
bodily appearance. The editors envisaged that the journal should address the topic of health as a phenomenon undergoing quite marked and remarkable change, not least being its dislocation from its binary connection with illness. This is not to say that health is not related to illness, but that the shaping of health - of the various ways of being healthy - owes something to changes that have been taking place both in medicine and in society, and hence in the relationship between them. Most importantly, there was a feeling that health had become a goal 'in itself', beyond the removal of disease, and mention was made of its de-differentiation resulting from the weakening of medical authority and the growth of consumerism in society. This has meant that being healthy, or the stress upon health promotion, are subject to a culture in which consumption is primary, and yet where individuals are made responsible consumers. By the end of the 1990s, health was no longer contained by its binary relationship to illness, and had come to inflect a range of previously separate areas of life and, in its turn, to be shaped by them (e.g. related to diet, exercise and beauty). How to become, or to remain healthy had become a major concern for many, not least because the goals and practices of 'good health' have been promoted by medical authorities and the mass media. Alongside this, being fit and healthy became (and remains) a sine qua non - where it could be economically afforded - for individuals wanting to prosecute an active and prosperous consumer lifestyle.

It was against this background that the opening editorial envisaged that articles to be published in health: would address issues to do with the representation of health and illness, not just the causes of disease and the progress of treatments. As well as this, there would be articles that dealt with the moral dilemmas that attached to the various decisions that had to be made in a world where there is so much choice about how to become and to stay healthy.

The ground that the journal sought to occupy was a territory that had been opened up by changes in society - particularly, as already pointed out, to do with the rise in consumerism - as well as by changes in medicine. The latter includes the policy of screening for signs of disease, justifying a seemingly ever-increasing surveillance and penetration of life by medical technology. Alongside technologies for seeing further into the body there are new techniques that locate and record details of individuals and populations, not least among these being the promised advances of the "new genetics'. These technological advances - both proximal and distal - require new practices that in turn give rise to moral and ideological debate about rights, opportunities and differences. Where these two developments meet - the consumerist culture and the new medical order that prioritizes risk is where we believed the problems for health: would be located. We recognized that this ground would be multifaceted, if only because the success of modern medicine enables people to survive serious disease, though it cannot teach them how to live with it or with the fear of its possible onset. 
The emergence during the 1990s of what has come to be called the 'remission society' (Frank, 1991) opens up possibilities for examining definitions of health in relation to lives lived with disease, either as individuals or with others who have undergone similar experiences.

As an examination of that opening editorial reveals, we also encouraged articles about other topics than the ones mentioned above. However, it was clear that an important focus for the journal was how people achieve, retain or regain a state called health, as well as how they help others in its mutual sustenance. The aim of the journal was to frame these issues in terms of changes in society and developments in medicine. With this attempt at a re-focus came the (implicit) charge that the research agenda had been too focused upon illness, in its various forms. Or rather, upon illness that presumed an understanding of health. The importance of this charge is that any understanding of illness and its treatment must be sought alongside an understanding of health in its various forms, and not, it needs to be said, as just the 'opposite' or the removal of illness. While this idea is not new, it seeks to undo the assumption that there is something called 'health' that has a unitary existence, so that it can readily be foregrounded, as in a study of 'health conceptions' or health behaviour, health psychology, etc.

One intended consequence of attempting to make the consumption of medicine, in its various forms, the journal's main priority was the encouragement of articles that might otherwise fall between disciplinary frameworks. While the journal was conceived within the framework of social theory, this idea was allowed to remain sufficiently broad so as to encompass approaches from sociologists, anthropologists, cultural theorists and psychologists writing in this area. As well as this, we hoped that people in the professions (medical, nursing and allied) might contribute articles drawing upon their own professional involvement.

To what extent have these hopes been realized and these anticipations confirmed? Certainly the range of articles has been wide, and has contributed over the years to issues of the journal that - we hope - have at times surprised and interested readers. (One of the aims of health: is to be a journal that always rewards the reader's inquiries, and occasionally surprises with its content. We want health: to be a journal whose content is read, not merely referenced, important though the latter is for impact-rating purposes.) Whether sufficient articles have been submitted and published that address the issue of health - of what health can or might be - is another matter. At first sight, considering articles in terms of their individual focus, the answer to this question is 'no'; and yet on looking again across the content there are signs that authors have been grappling with issues that bear upon precisely the focus that we set up at the outset of the journal. And on reflection, why should we expect our authors to set out explicitly conceptualizations that we - as editors - framed only in general terms as forming the aims of the journal? The question is, rather, have authors of articles in health: been pointing to features of the problematic - to health 
in all its complexity - that are, quite simply, not easy to articulate for reasons that have not yet been examined in sufficient detail?

In addressing this question, we shall be focusing upon articles published in this journal alone rather than reviewing the field in general. This might seem too narrow an enterprise, perhaps even a conceit, but the aim here is to examine whether there is a conceptualization of health that can be gained from a reading of the journal to date (effectively, the first nine volumes). What can we learn from the authors who have placed their work here? In choosing health: as the outlet for their work, what have they pointed out about issues that the editors were keen should be addressed in that first number?

\section{Medical technology shapes health}

In her description of the development of telemedicine during the 1990s, Cartwright (2000) drew attention to the way that being able to extend health care to previously underserved populations has allowed two things to happen. First, it re-ordered these people along new dimensions, overcoming original geographic differences, so as to make these new populations 'remote locals'. The techniques employed to do this can be seen as comprising a 'benign' organization that allows, or even demands, that new practices be implemented to meet ends defined in terms of its parameters. Effectively, distance is overcome in the course of features (about health) being combined and transmitted in new ways. Health can be managed at a distance. The second consequence of telemedicine is that individuals in these populations are encouraged to take on responsibilities for their health through the intermediation of professionals in their locale, who are 'brought up to standard' by the requirement to engage with the new technology. Cartwright argues that telemedicine does not simply eradicate distance but can be used, where deemed necessary, to contain health crises in remote regions and protect health 'at home'. (In this way it can be used to reinforce boundaries, just as was the case in previous times, such as in the use of quarantine to control entry of immigrants to Australia (Bashford, 1998).) Perhaps more important is its organizing practice that allows telemedicine to imagine 'health communities' in the course of transmitting back information about them, so as to change their categorical status. It reaches across the globe to make available standards of medical care that would not otherwise be available (without movement of people) and also to encourage forms of health care that can replace those used locally. What Cartwright makes clear is that telemedicine does not contain particular ends, making these certain. For example, she shows the uncertainty of knowing, in particular circumstances, whether telemedicine will result in profit or not-for-profit delivery.

The idea of imagining new communities of people is not dissimilar from the apprehension that the new genetics would create virtual ghettos of 
at-risk individuals. From a different perspective Waldby (2002) argues that the new technologies (which include stem cell techniques) 'fragment' individuals according to lines that do not support their identity as persons. Waldby asks about the status of such fragments - genetically labelled, organized by human cell lines - as they are potentially transferred between people, or offered for sale. She raises questions about the economies that the transfer - the gifting - of cell tissues creates, and points to the potential for stem cells to be seen as offering forms of health that are not compromised by either immuno-suppression or indebtedness, both required by existing organ donation. However, were this to happen, the implication is that the production of fragments of tissue that circulate in a new health economy will create new dilemmas and perhaps opportunities for people who receive these biological supplements. Among these, as Waldby points out, are issues arising from what she sees as the difficulty of reconciling the ideal of the gift with the production of an economy in which 'biovalue' becomes a traded item. What is imagined in this case is an economic community based upon the transfer of material. This results in a distancing of persons through commodification, voiding exchanges of indebtedness and thereby problematizing the local. This brings the market into areas hitherto unimagined.

Both of these innovations in medical technology, in their different ways, are shown to be important for undoing traditional relationships between doctors and patients and dissolving hitherto established boundaries between health professionals on the one hand, and members of the community on the other. On both representational and material planes these innovations create spaces and configure new assemblies while keeping open the possibility of developments in the deployment of powers. On the one hand, individuals are dislodged from their traditional communities as they are re-designated at a distance; on the other hand, people are separated from, and can be connected to samples of body tissue that circulate in a system of exchange. In consequence, decisions about the actual and potential locus of disease and the practices that might forestall it shift to criteria that inhere in the parameters of these new systems. This creates different and sometimes problematic issues for health care provision, where the causes of ill health - or the resources of good health - are seen still to reside in relationships that the new technologies have loosened if not undone. For example, in the field of HIV/AIDS, the risk of particular individuals becoming infected has been regarded in the past as an external risk, and subject to the self-discipline of individuals. Now, it has been argued, the actions (or lack of them) of the public infrastructure turns this disease into something like a 'manufactured risk'. Mooney and Sarangi (2005) show how the scale and spread of HIV in the developing world is closely associated with actions in the spheres of public health, education and the organization of societies. The growth of telemedicine - with its reach from developed centres of clinical expertise to rural districts of far-away 
countries - can be seen as contributing to a similar sort of shift in the attribution of risk and responsibility. Given that conceptions of health - of health maintained, health conserved - involve judgements about the handling of risk, then these innovations produce new nodal points of expertise, new confluences of judgement, new spaces of uncertainty about what 'good health' could or should be and of course new experts and new groups to 'blame'.

The case of HIV is interesting in having been a focus for research in recent years into the variation and course of the virus itself. Here is a disease that became the basis of a re-identification of people with their acquired compromised health status. This identification was conditional upon what has been called the common denominator of 'the discrete individual body that could be given a status (i.e. HIV antibody negative)' (Flowers, 2001: 67). Flowers argues that the advent of new technologies allowing testing of viral activity and progression in different body parts means that the communality of gay men is undermined by the differences between individuals. This is a further twist in the ongoing re-definition of risk by screening but it is also more than this. In line with Waldby's argument, it reflects a separation of individual from unified body. The fragmentation of the body in its separately affected constituent parts problematizes the relationship between person (self) and body, as well as between persons who are affected by HIV. This complicates both definitions of health in terms of screening results and, equally importantly, raises new questions about health statuses that are referred to a social self. Examining the accounts of men living with HIV, Persson et al. (2003) conclude that these men live in a world of process and practice rather than of separate loci of health and illness. The ongoing shifting dialogue between the various discourses in and outside of the clinic contributes to what these authors term a 'functional dis-integration' that fosters negotiation and recombination of themes that supports a sense of well-being. Alongside the uncertainty created by new technologies there exists the potential for re-conceptions of what it means to be well, where these ideas will inevitably be implicated in the shifting definitions of health and illness.

Outside of the clinic, the power of medical technology to affect people's lives continues in ways anticipated at the time of the launch of this journal. Screening for disease using indicators of difference and variance position individuals 'at risk' when they are symptom free, contributing to a political world in which self-surveillance and individual responsibility are watchwords in the emergence of a culture that seeks to police the boundaries of health along new lines, not just geographic, not just socio-structural (Robertson, 2001). In the introductory article to the first issue of health: we posed the question whether health is metaphorical, and what the nature of those metaphors might be. In a recent essay on risk, Crawford (2004) borrows from Comaroff (1982) to argue that policing of the boundaries is not the victory of neo-liberalism that it is often portrayed to be, but a ritual 
practice, a kind of secular ritual. The concept of health here refers not to a sense of well-being but, in contrast, to the displacement of anxiety through practices - born of technological innovation - that confer efficacy through ritual, through 'metaphor that is meant'. This anxiety is not restricted to members of the public. It also touches professionals, for whom determining and maintaining a belief in the efficacy of methods (e.g. the evidencebased movement) associated with technology extends to moral denigration of those who do not accept them (Traynor, 2000).

This means that there is a difference between the view that health is being shaped up - inexorably - by medicine and the idea that practices and discourses about health confer powers through ritual. From this perspective, it would appear that the price of allaying anxiety (about risk of disease and death) is, for some, the belief in the powers of technology to determine good health. This squares with the idea that far from being deterministic, new technologies provoke discourses and practices that are open as to the status that they will confer upon the material conditions that made them possible.

\section{Rights and the remission society}

The introductory article in the first issue of health: contained no reference to the Internet. Perhaps we did not see its potential coming because it had just arrived. Whatever the case, the Internet has not only become a primary tool for accessing medical information but it has also emerged as the vehicle for pooling experiences of illness and treatment. In a world of individual rights, the Internet holds out the possibility of people finding their voice, and yet it also furthers individualism in the form of promoting self-responsibility, if not for disease then for how one manages one's illness (Pitts, 2004). As Hardey (2002) points out, 'home pages' do not dwell on sickness but on the re-establishment of fitness and the recovery of the highest quality of life possible within the constraints of illness. This recovery is not simple, given that the project is premised upon an unravelling of the certainties of medicine, so that risk extends to the ways that people who are already living with serious disease conduct their lives. This runs the risk of a new form of moralism concerning how to do this, making those who are unable to follow this line appear as 'failures'. Accessing the Net is not a gateway to the truth but is perhaps more like entering a breach in the monolith of what being ill might mean. The diversity of information, opinion and recommendation results in the necessity for people to apportion, weight, select and balance what they see and hear. This in turn creates debates about the location of expertise and the legitimacy of rights to speak.

Use of the Internet for information is instructive for appraising the relationship between the global reach of technology and its appropriation by users seeking mutual support. Drawing on the work of Fiske (1993), Goldstein (2000) takes up the idea that globalizing technologies establish 
'stations' in the extension of their horizons. These are nodal points that users, through discourse, turn into locales that celebrate the vernacular. She argues that this can be applied in the case of Internet support groups, so that there is the possibility of the vernacular being elaborated not only in its cultural context (as locale), but of it also being mobilized in the cause of activism.

This is not merely a case of the local supplanting the global, or the lay view being celebrated over the medical perspective. Goldstein's chosen example - the case of menopausal women - shows how the women 'carve out a space to act' between the restrictive biomedical definitions of menopause and the limiting interpretations of feminists who replace the medical with the social (Patton, 2000: 279). The implications of this for understanding health relate once more to the way in which innovative technologies (this time not medical) position people in new ways that provoke their response, either individual or collective. Deciding what is 'healthy' is, in a way, not the appropriate question any more. How to achieve a sense of well-being, and with that a sense of personal and collective worth, becomes a primary aim.

This challenge exists even for people who are aided directly by medical technologies, such as people who are deaf. In his article that uses the phrase 'carving out a space to act' as its title, Hogan (1998) argues that deaf people do not inevitably want to move into a hearing culture, say by the aid of a cochlear implant. For some deaf people the establishment of a new identity involves a heterogeneity of practices, enabling a moving between worlds of hearing and non-hearing people. The idea of a 'new identity' is not dissimilar to the outcome of the search that Frank (1997) says is undertaken by those suffering serious illness. For Frank, the morality of illness is about seeking to do the right thing, responding to the question, 'How do I become the sort of person who has to live with a decision that I never should have had to make?' These choices are made in a world of uncertainties, but also one in which the risks involve not a threat to health as much as a threat to integrity, where one's health has already been breached. However, in this case, in a remission society, the therapeutic benefits of modern medicine create in each survivor a nodal point (a nodal space, if that is possible) in which the vernacular can rise. And the morality of illness is such that where people move from being mere survivors to being witnesses of suffering and treatment then the vernacular reaches back to embrace others, both outside of and inside medicine. In relation to other people, Frank poses the question of how the ill can become - without patronage - the object of others' solicitude (1998: 344), a practice that has, as one of its aims, the establishment of a positivity in illness (an illness culture), which emerges as complementary to health, not merely its shadow side.

Taking the second point, 'reaching back' from the local also extends into medicine, as so often exemplified in stories written by people who feel let down by its efforts even as it sought to help them. The writ of local culture 
is by definition limited, and none more so than when it reaches the doors of the clinic. What rights do patients have - and what rights do patients' families have - in the hospital? In her biographic account of the treatment of her brother-in-law who was to die of his injuries, Weitz (1999) demonstrates the opposing views of doctors and some of the patient's relatives. The primacy of treatment in ITU, where technology is therapeutically at its most intense, is shown to emerge dominant over concerns that might be termed more local. Weitz offers a sociologically informed account of these happenings, and by rising above the local to employ the language of sociology, opens herself to the potential charge that she misses the ambiguities of the situation (Ellis and Bochner, 1999: 235). This raises the question of the way in which the practices and discourses of health and illness should be reported, in particular how the significant features of 'the local' can or should be preserved in reporting their commerce with 'the general'. The emergence of a remission society, together with the increased use of technology like the Internet, makes these matters of continuing importance for students and scholars of health.

The achievements of modern medicine in saving and prolonging life have been brought about by technologies that produce not only 'stations' of therapeutic uncertainty but also 'locales' of witness - in short, survivors who live in the shadow of medical check-ups and yet strive to live ethically. Articles that have been published in the journal over the past 10 years are testimony to the way in which this 'reaching back' problematizes our conceptions of health and illness so that what was formerly seen as a 'grey area' (lying somehow between the two) is recast as the crucible of a sense of well-being. This is made possible by dialogue and ethical practice that arises in spaces created by the forays of technology and politics into health care.

\section{An understanding of health?}

We have said that a primary aim of the journal has been to question whether research into illness should presume an understanding of health as a unitary phenomenon. Certainly, contributors addressing theoretical issues around this topic have varied in their ideas about the role of pleasure/discipline in the regulation of what is deemed to be healthy (Williams, 1998; Crawford, 2004). It might be that the relative breakdown of normative assumptions in this area means that the notion of healthy practices is all that now remains, even where these are given the approval of governments and agencies in public health packages. The fragmentation and deployment of practices enables the inclusion of 'health' (or at least its indices) into every corner of consumer culture, today extending to the offer of cosmetic surgery as a competition prize. 'Health' is not even something that you have to work at any more; it can now be consumed like the latest pro-biotic drink. It is not surprising that one critic of consumerist culture, Susan Sontag, railed against this development: 
What has followed in the wake of 1989 and the suicide of the Soviet empire is the final victory of capitalism, and of the ideology of consumerism, which entails the discrediting of 'the political' as such. All that makes sense is private life. Individualism, and the cultivation of the self and private well-being - featuring, above all, the ideal of 'health' - are the values to which intellectuals are most likely to subscribe. (2002: 328)

At one level it might be concluded that the emergence of 'healthism' - with its detachment from illness - means that there is little here for the student of medicine in modern society. However, this would be to miss the point that the very cultural developments that produce this idea of health is also one in which there is increased scope for people to relate differently to medicine. Examining the first nine volumes of health: there is comparatively little about health as distinct from illness. On the basis of the 1997 introduction to the journal, readers might have expected more articles dealing with health per se. We thought then that the very fact that health is ideological - that it is shot through with cultural assumptions - might make it an ideal topic for contributions to the journal. Perhaps Sontag's criticism provides, implicitly, the reason why this has not happened - at least in the pages of this journal. Once health is detached from illness, once its root in suffering and mortality is cut away, then the practices and discourses that promote, shape and channel it derive increasingly from that area of life that we know as 'lifestyle'. And this seems to be more the province of something other than medical anthropology, the sociology of medicine or health psychology. Health is distanced from illness at the risk of becoming vacuous in the eyes of these sub-disciplines, or at least of making the theorizing of pleasure problematic (Coveney and Bunton, 2003).

In the first volume of health: Frank wrote that, 'Disease is not the absence of health; rather, health and illness are the complementary cycles of the world' (1997: 141). A sense of well-being requires a moral weighting of collective compassion and a recognition of individual vulnerability (Radley, 1999; Little et al., 2000); it must include the potential for illness within itself. This is another way of saying that there are no studies of health without illness; some might go further and say that there can be no understanding of health outside of attention to developments in medical technology or in alternative medicine. To borrow a phrase from medicine, health is occult; this is not only in the sense that it is not manifest but also that it appears and disappears. The occulting of health is something that has previously been related to the onset of illness, as in Leder's (1990) description of the 'dys-appearing body'. On the basis of the articles mentioned in this overview, we might say that the occulting of health relates to the cycle of practices and technological interventions that counter illness and take the measure of disease. This is to turn upside down the notion that health is the extensive background to life that the advent of illness foregrounds, and of which we then become aware. Research into responses to distinct diseases and the organization of medical care continues to rest upon and 
maintain this assumption. We can - on the basis of research published in this journal - at least attempt a tentative but intriguing alternative proposition. This proposal is based upon the growing presence of medicine, both globally and in the interstices of daily life. We suggest that this development disrupts health as extensive, as a background to the appearance of disease and illness. In consequence, people respond through dialogue and sociality, so that health now appears fractionally and in multiple forms within the modern context of vulnerability and risk. In conclusion then, can we take for granted any more the 'taken for grantedness' of health?

\section{References}

Bashford, A. (1998). Quarantine and the imagining of the Australian nation. health: An Interdisciplinary Journal for the Social Study of Health, Illness and Medicine, 2(4), 387-402.

Cartwright, L. (2000). Reach out and heal someone: Telemedicine and the globalization of health care. health: An Interdisciplinary Journal for the Social Study of Health, Illness and Medicine, 4(3), 347-77.

Comaroff, J. (1982). Medicine: Symbol and ideology. In P. Wright and A. Treacher (Eds.), The problem of medical knowledge, pp. 49-68. Edinburgh: Edinburgh University Press.

Coveney, J. and Bunton, R. (2003). In pursuit of the study of pleasure: Implications for health research and practice. health: An Interdisciplinary Journal for the Social Study of Health, Illness and Medicine, 7(2), 161-79.

Crawford, R. (2004). Risk ritual and the management of control and anxiety in medical culture. health: An Interdisciplinary Journal for the Social Study of Health, Illness and Medicine, 8(4), 505-28.

Ellis, C. and Bochner, A. (1999). Bringing emotion and personal narrative into medical science. health: An Interdisciplinary Journal for the Social Study of Health, Illness and Medicine, 3(2), 229-37.

Fiske, J. (1993). Power plays, power works. London: Verso.

Flowers, P. (2001). Gay men and HIV/AIDS risk management. health: An Interdisciplinary Journal for the Social Study of Health, Illness and Medicine, 5(1), 50-75.

Frank, A.W. (1991). At the will of the body: Reflections on illness. Boston, MA: Houghton Mifflin.

Frank, A.W. (1997). Illness as moral occasion: Restoring agency to ill people. health: An Interdisciplinary Journal for the Social Study of Health, Illness and Medicine, 1(2), 131-48.

Frank, A.W. (1998). Stories of illness as care of the self: A Foucauldian dialogue. health: An Interdisciplinary Journal for the Social Study of Health, Illness and Medicine, 2(3), 329-48.

Goldstein, D.E. (2000). 'When ovaries retire': Contrasting women's experiences with feminist and medical models of menopause. health: An Interdisciplinary Journal for the Social Study of Health, Illness and Medicine, 4(3), 309-23.

Hardey, M. (2002). 'The story of my illness': Personal accounts of illness on the Internet. health: An Interdisciplinary Journal for the Social Study of Health, Illness and Medicine, 6(1), 31-46.

Hogan, A. (1998). Carving out a space to act: Acquired impairment and contested 
identity. health: An Interdisciplinary Journal for the Social Study of Health, Illness and Medicine, 2(1), 75-90.

Leder, D. (1990). The absent body. Chicago, IL: University of Chicago Press.

Little, M., Paul, K., Jordens, C.F.C. and Sayers, E.-J. (2000). Vulnerability in the narratives of patients and their carers: Studies of colorectal cancer. health: An Interdisciplinary Journal for the Social Study of Health, Illness and Medicine, 4(4), 495-510.

Mooney, A. and Sarangi, S. (2005). An ecological framing of HIV preventive intervention: A case study of non-government organizational work in the developing world. health: An Interdisciplinary Journal for the Social Study of Health, Illness and Medicine, 9(3), 275-96.

Patton, C. (2000). Introduction. Helping ourselves: Research after (the) enlightenment. health: An Interdisciplinary Journal for the Social Study of Health, Illness and Medicine, 4(3), 267-87.

Persson, A., Race, K. and Wakeford, E. (2003). HIV health in context: Negotiating medical technology and lived experience. health: An Interdisciplinary Journal for the Social Study of Health, Illness and Medicine, 7(4), 397-415.

Pitts, V. (2004). Illness and Internet empowerment: Writing and reading breast cancer in cyberspace. health: An Interdisciplinary Journal for the Social Study of Health, Illness and Medicine, 8(1), 33-59.

Radley, A. (1999). Abhorrence, compassion and the social response to suffering. health: An Interdisciplinary Journal for the Social Study of Health, Illness and Medicine, 3(2), 167-87.

Radley, A., Lupton, D. and Ritter, C. (1997). Editorial. health:: An invitation and introduction. health: An Interdisciplinary Journal for the Social Study of Health, Illness and Medicine, 1(1), 5-21.

Robertson, A. (2001). Biotechnology, political rationality and discourses on health risk. health: An Interdisciplinary Journal for the Social Study of Health, Illness and Medicine, 5(3), 293-309.

Sontag, S. (2002). Where the stress falls. London: Jonathan Cape.

Traynor, M. (2000). Purity, conversion and the evidence based movements. health: An Interdisciplinary Journal for the Social Study of Health, Illness and Medicine, 4(2), 139-58.

Waldby, C. (2002). Stem cells, tissue cultures and the production of biovalue. health: An Interdisciplinary Journal for the Social Study of Health, Illness and Medicine, 6(3), 305-23.

Weitz, R. (1999). Watching Brian die: The rhetoric and reality of informed consent. health: An Interdisciplinary Journal for the Social Study of Health, Illness and Medicine, 3(2), 209-27.

Williams, S. (1998). Health as moral performance: Ritual, transgression and taboo. health: An Interdisciplinary Journal for the Social Study of Health, Illness and Medicine, 2(4), 435-57.

\section{Author biographies}

ALAN RADLEY is Editor of health: and, together with Sage Publications, founded the journal in 1995.

JULIANNE CHEEK has been co-editor of the journal since 2002.

CHRISTIAN RITTER has been co-editor of health: since its foundation. 